\title{
Lifetime Modelling for MCrAIY Coatings in Industrial Gas Turbine Blades
}

\author{
Pavel Krukovsky $^{\mathrm{a} *}$, Konstantin Tadlya ${ }^{\mathrm{a}}$, Alexander. Rybnikov ${ }^{\mathrm{b}}$, Iosif Kryukov ${ }^{\mathrm{b}}$, \\ Natalia Mojaiskaia $^{\text {b }}$, Vladislav Kolarik ${ }^{\mathrm{c}}$, Maria Juez-Lorenzo ${ }^{\mathrm{c}}$ \\ anstitute of Engineering Thermophysics, 2a, Zhelyabov str., 03057 Kiev, Ukraine \\ ${ }^{\mathrm{b}}$ Polzunov Central Boiler and Turbine Institute \\ Politechnicheskaya, 24, 194021 St. Petersburg, Russia \\ ${ }^{\mathrm{c}}$ Fraunhofer-Institut für Chemische Technologie \\ Joseph-von-Fraunhofer Str. 7, 76327 Pfinztal, Germany
}

Received: September 2, 2002; Revised: September 4, 2002

\begin{abstract}
A novel theoretical and experimental approach for lifetime modelling of MCrAlY coatings for stationary gas turbines has been undertaken using the Inverse Problem Solution (IPS) technique. With this technique feasible experimental data acquired after a defined experimental time $\tau_{\mathrm{e}}$ are used as input values for the model parameters estimation. In the first stage of the approach a model, based on the oxidation and diffusion processes (Fick's first and second law) was assumed, which considers the $\mathrm{Al}$ concentration profile across the coating. The measured average $\mathrm{Al}$ concentration profiles in the two-phase $\gamma+\beta$ and $\gamma$-regions of coating as well as base metal were used as input values for the model parameters estimation and calculational prediction of the long term diffusion and oxidation behavior of the coating was performed. The time, when the $\beta$-NiAl phase is completely consumed was assumed as the coating lifetime end. Exposure experiments were carried out with a NiCoCrAlY coating (200 micron thickness) with $8 \% \mathrm{Al}$ in air at $900{ }^{\circ} \mathrm{C}$ and $950{ }^{\circ} \mathrm{C}$, currently up to $10000 \mathrm{~h}$. The oxide scale is growing continuously and no other oxides were observed. The average and $\beta-\mathrm{NiAl}$ phase concentration profiles of $\mathrm{Al}$ across the coating thickness were determined by electron microprobe and image analysis systems in the initial state after 700 and $10000 \mathrm{~h}$ of oxidation. The concentration profile measured after $700 \mathrm{~h}$ was used as input values for the model parameters estimation in order to calculate the $\mathrm{Al}$ and $\beta$-NiAl phase concentration profiles after $10000 \mathrm{~h}$. The computational forecast for $10000 \mathrm{~h}$ at $950{ }^{\circ} \mathrm{C}$ and $900{ }^{\circ} \mathrm{C}$ are in good agreement with the measured data. The approach was applied for NiCoCrAlY (200 micron thickness) coating lifetime modelling at $950{ }^{\circ} \mathrm{C}$ and $900{ }^{\circ} \mathrm{C}$ as well as for different coating thicknesses at $950{ }^{\circ} \mathrm{C}$.
\end{abstract}

Keywords: gas turbines blades, coatings, lifetime modelling, inverse problem

\section{Introduction}

In modern stationary gas turbines for electric power generation MCrAlY type coatings are used world-wide for protective overlay coatings against oxidation ( $\mathrm{M}$ comprises $\mathrm{Ni}$ and/or Co) ${ }^{1,2}$. In future developments higher gas inlet temperatures are envisaged for a further increase of the turbine efficiency and for more economic use of the energy resources. Higher temperatures however, lead to a significantly increased oxidation attack and accelerated diffusion processes at the coating - substrate interface ${ }^{1}$.

*e-mail:kruk@i.kiev.ua

Presented at the International Symposium on High Temperature Corrosion in Energy Related Systems, Angra dos Reis - RJ, September 2002.
The technological developments in stationary gas turbines for electric power generation as well as strengthened safety requirements for their operation imply the necessity of reliable lifetime prediction procedures for $\mathrm{MCrAlY}$ coatings. The reliability of such a lifetime prediction procedure however, depends not only on the applicability of the physical and mathematical model, on which it is based, but furthermore on the feasibility of the determination of the modelling parameters in practice. The latter is at least of equal 
importance as an applicable model of the oxidation and diffusion processes in an MCrAlY coating.

In the case of the MCrAlY coatings the protection against oxidation is achieved by the formation of a thin $\mathrm{Al}_{2} \mathrm{O}_{3}$ layer on the coating surface. The $\mathrm{Al}$, which generally is found as a $\beta$-NiAl phase in the coating, is consumed by both $\mathrm{Al}_{2} \mathrm{O}_{3}$ formation at the surface and by interdiffusion at the substrate coating interface, producing aluminium depletion zones that increase with time and temperature. When the $\beta$-NiAl phase is completely consumed and the $\mathrm{Al}$ concentration reaches a critical minimum value, other oxides like $\mathrm{Cr}_{2} \mathrm{O}_{3}$ and/or spinels may form besides the protective alumina, leading to internal oxidation $^{1}$. The time, when the $\beta-\mathrm{NiAl}$ phase is completely consumed is assumed as a coating lifetime end.

So, the long term modelling of $\mathrm{Al}$ oxidation and diffusion processes in $\mathrm{MCrAlY}$ coatings until the $\beta$-NiAl phase disapears is the main object of the coating lifetime end estimation.

There are models which describe the main physical and chemical processes during the oxide scale and depletion zones formation based on the Fick's first and second laws s.4 $^{3,4}$ and deliver therefore reliable prediction of the oxidation and diffusion processes. For a reliable quantitative application of latter models however, parameters must be known, which are needed for the calculation. Such parameters are for example diffusion coefficients of the oxide forming element and the kinetic rate constants for the oxide formation. For the modelling and lifetime prediction reported in ${ }^{5}$ for instance, special experiments and calculation techniques were used for the determination of the diffusion coefficients in $\mathrm{Ni}-\mathrm{Cr}-\mathrm{Al}$ alloys at 1100 and $1200{ }^{\circ} \mathrm{C}$. Furthermore, experiments had to be carried out to determine the rate constants of the $\mathrm{Al}_{2} \mathrm{O}_{3}$ formation.

The main innovative aspect of the approach described in the present work is the application of the Inverse Problem Solution technique (IPS) to determine the quantitative

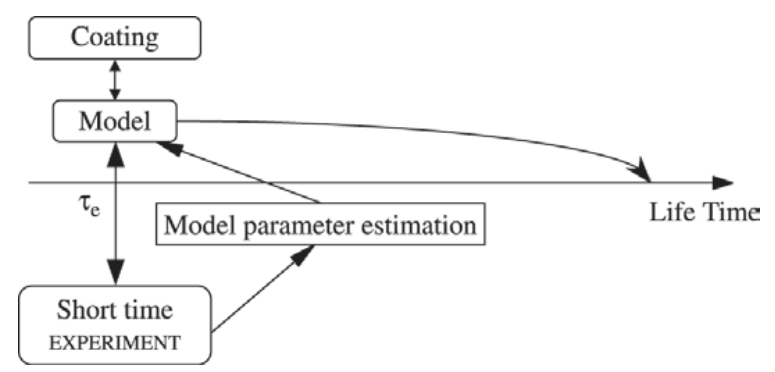

Figure 1. Scheme of the Inverse Problem Solution technique for model parameter estimation and life time prediction. values of the model parameters. In the case of the lifetime modelling of MCrAlY coatings only the concentration profile of $\mathrm{Al}$ across the coating thickness measured after a defined time $\tau_{\mathrm{e}}$ of exposure is needed as input values (Fig. 1). All model parameters needed for the modelling like the effective diffusion coefficients are then determined by the IPS technique and used for the forecast calculation. Thus the IPS technique allows an economic quantitative lifetime modelling, which is easily feasible in practice, and enables long-term prediction using experimental data from short exposure times, supposed that no change in the relevant mechanisms occurs.

\section{Modelling Approach}

A typical transversal concentration profile of an oxideAl forming element in the coating near region of the base alloy is shown schematically in Fig. $2^{4}$.

In the case of the MCrAlY coatings the protection against oxidation is achieved by the formation of a thin $\mathrm{Al}_{2} \mathrm{O}_{3}$ layer on the coating surface $\left(\mathrm{x}_{1}-\mathrm{x}_{0}\right)$. The $\mathrm{Al}$, which generally is found as a $\beta-\mathrm{NiAl}$ phase in the coating, is consumed by both $\mathrm{Al}_{2} \mathrm{O}_{3}$ formation at the surface and by interdiffusion at the substrate - coating interface, producing aluminum depletion zones that increase with time and temperature.

A physical and mathematical model considering the $\mathrm{Al}$ concentration profile across the coating was applied according to $^{4}$. In our case we used the above mentioned model with an effective diffusion coefficient of aluminum $\mathrm{D}_{\mathrm{Al}}$. In Fig. $2 \mathrm{C}_{\gamma+\beta}$ is the average aluminum concentration in the twophase $\gamma+\beta$ - region, $C_{\gamma}$ is the interfacial concentration of aluminum at the $\gamma / \gamma+\beta$ interfaces. $C_{\gamma+\beta}$ is determined by the volume fraction and the equilibrium concentration of each phase in the two-phase region ${ }^{4}$. The physical model takes into account that during the oxidation the oxide surface $\mathrm{x}_{0}$ moves outwards, while the boundaries $\mathrm{x}_{1}$ move inwards into the coating alloy, $x_{2}$ and $x_{3}$ move towards each other. Time,

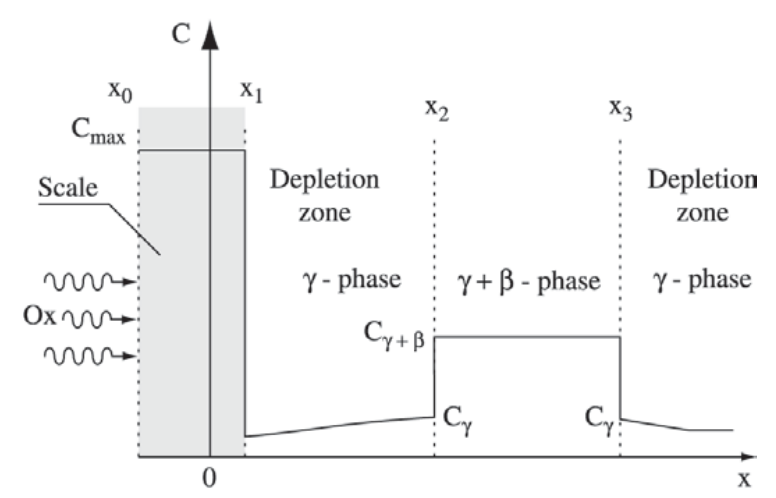

Figure 2. Concentration profile of the $\mathrm{Al}$ alloying element. 
when the $\beta$-NiAl phase is completely consumed, may be assumed as a coating lifetime end.

The modern models for modeling the oxidation and diffusion processes in MCrAlY coatings (Fick's first and second law) like mentioned above usually can't be used with good accuracy for lifetime prediction due to unknown model parameters for the complicated MCrAlY coating compositions. The physical and mathematical model under consideration comprises three kind of input data, which must be known for the prediction of the oxidation and diffusion processes: the $\mathrm{D}_{\mathrm{Al}}$ effective diffusion coefficient of aluminum, the $C_{\gamma}$ interfacial concentration of aluminum at the $\gamma / \gamma+\beta$ interfaces and oxide scale growth low.

\section{Lifetime Prediction by Inverse Problem Solution (IPS)}

The main innovative aspect of the approach described in the present work is the application of the Inverse Problem Solution technique (IPS) to determine the quantitative values of the model parameters. This technique was considered in ${ }^{6,7}$ for modeling a single-phase coatings.

In the case of the lifetime modeling of MCrAlY coatings the concentration profile of $\mathrm{Al}$ across the coating thickness measured after a defined time $\tau_{\mathrm{e}}$ of exposure to temperature is needed as input value only. All model parameters needed for the modeling like $\mathrm{D}_{\mathrm{Al}}$ are then determined by the IPS technique and used for the predictive calcula-

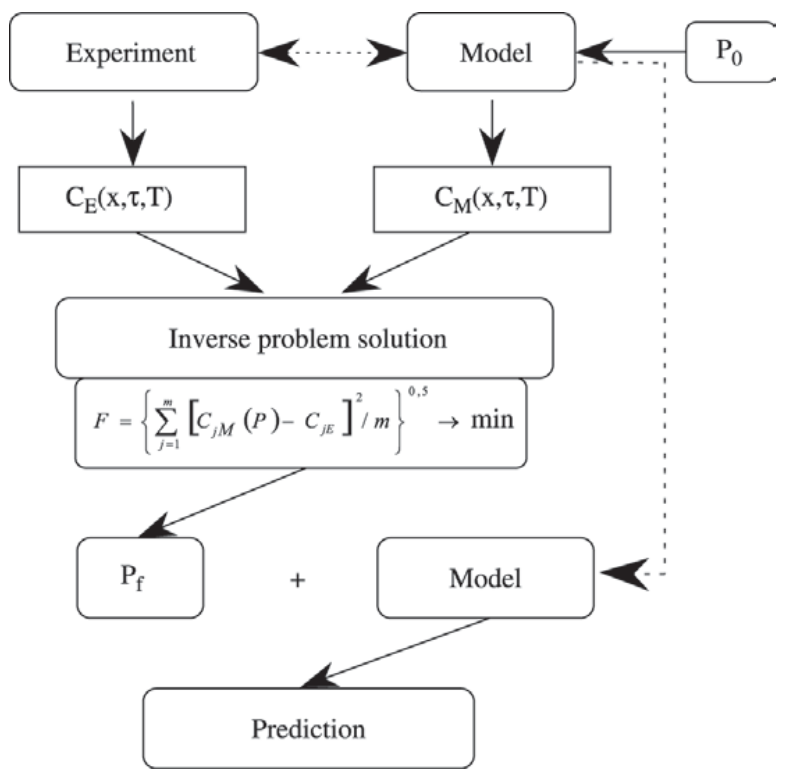

Figure 3. Scheme of computational and experimental approach for oxidation and diffusion processes prediction using the IPS method tion. Thus the IPS technique allows an economic quantitative lifetime modeling, which is easily feasible in practice, and enables long term prediction using short time experimental data, supposed that no change in the relevant mechanisms occurs.

The approach (Fig. 3) consists of four fundamental steps:

1. Design of a mathematical model or the use of an existing one.

2. Experiments with given experimentation time and temperature delivering input data for the model parameter estimation.

3. Estimation of the key parameters of the mathematical model for different temperatures (calibration of mathematical model).

4. Computational prediction of the alloying element distributions and coating lifetime end.

Using the Inverse Problem Solution technique the concentration profile of $\mathrm{Al}$ across the coating thickness $\mathrm{C}_{\mathrm{E}}$ is needed as experimental input data for the calibration of the mathematical model. For the estimation of the model parameters $\mathrm{D}_{\mathrm{Al}}$, and $\mathrm{C}_{\gamma}$ the following convergence criterion is applied:

$$
\mathrm{F}=\left\{\sum_{\mathrm{j}=1}^{\mathrm{m}}\left[\mathrm{C}_{\mathrm{jM}}(\mathrm{P})-\mathrm{C}_{\mathrm{jE}}\right]^{2} / \mathrm{m}\right\}^{0,5} \approx \delta,
$$

where $\mathrm{P}=\mathrm{P}\left(\mathrm{D}_{\mathrm{Al}}, \mathrm{C}_{\gamma}\right)$ is the unknown model parameter vector, $\mathrm{C}_{\mathrm{j}, \mathrm{M}}$ and $\mathrm{C}_{\mathrm{j}, \mathrm{E}}$ are the calculated and measured $\mathrm{Al}$ concentrations at the $\mathrm{j}^{\text {th }}$ measuring point of the concentration profile at a given position $\mathrm{x}$, time $\tau$ and temperature $\mathrm{T}, \mathrm{m}$ is the number of the measuring points, $\delta$ is the average square root error. The fit procedure of the model parameters is iterated until $\mathrm{F}$ reaches the given limit of $\delta$, which is $0.8 \%$ in the present case.

For performing the lifetime modelling approach by Inverse Problem Solution with the selected MCrAlY coating the following assumptions were considered:

- One alloying element only, in the present case the aluminium, forms the oxide scale.

- Oxidation and diffusion mechanism and model parameters do not vary with the time.

- The oxide scale formation occurs at the boundary $\mathrm{x}_{1}$.

- The diffusion coefficients of the $\mathrm{Al}$ alloying element $\mathrm{D}_{\mathrm{Me}}$ are constant and are effective empirical parameters obtained by short-time experiments with IPS.

\section{Experimental}

Exposure experiments were carried out for a $200 \mathrm{mi}-$ cron NiCoCrAlY coating thickness with $8 \% \mathrm{Al}$ in air at 900 and $950{ }^{\circ} \mathrm{C}$. The oxide scale growth low was obtained from 
experiment with approximation of the experimental data as a two parabolic curves (see Fig. 4). The oxide scale is growing continuously and no other oxides were observed. The

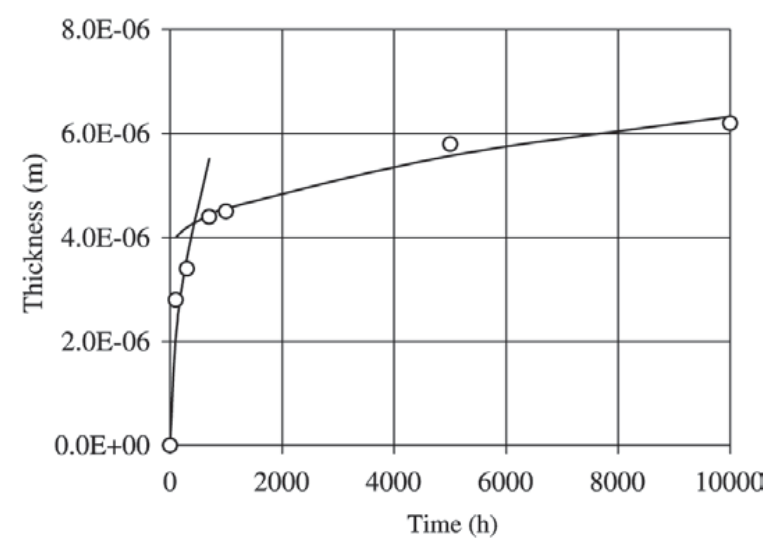

Figure 4. Oxide thickness during isothermal oxidation at $950{ }^{\circ} \mathrm{C}$ (points are the experimental data).

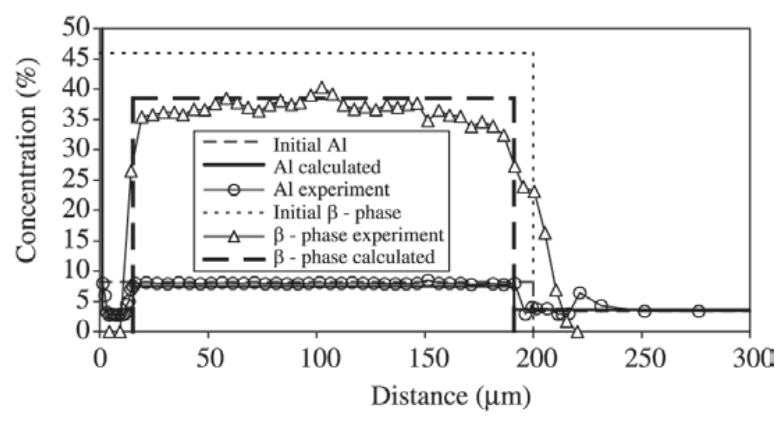

Figure 5. Measured and calculated total $\mathrm{Al}$ concentration profile (weight $\%$ ) and $\beta$ - phase (volume $\%$ ) across the coating and base metal after $700 \mathrm{~h}$ at $950{ }^{\circ} \mathrm{C}$.

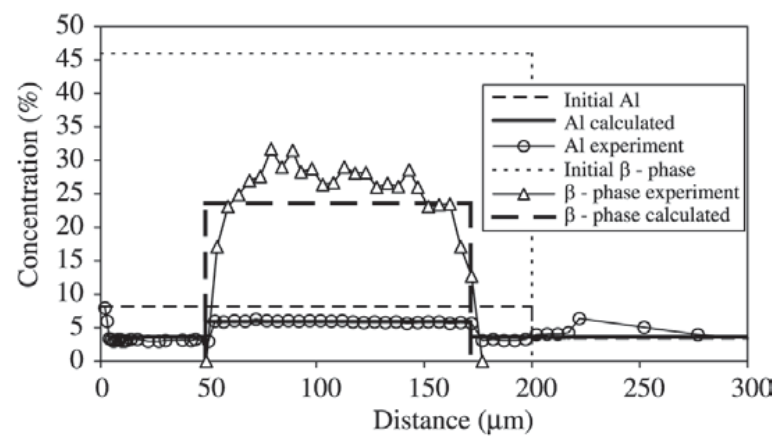

Figure 6. Measured and calculated total $\mathrm{Al}$ concentration profile (weight \%) and $\beta$ - phase (volume \%) across the coating and base metal after $10000 \mathrm{~h}$ at $950^{\circ} \mathrm{C}$.
Al concentration profile (weight \%) across the coating and base metal was determined by electron microprobe analysis after $700 \mathrm{~h}$ (Fig. 5) and $10000 \mathrm{~h}$ (Fig. 6). $\beta$-phase concentration profile (volume \%) was determined by an optical image analysis system.

\section{Results}

The measured concentration values $\mathrm{C}_{\mathrm{jE}}$ (Al total concentration) after $700 \mathrm{~h}$ (Fig. 5) were used to estimate the coefficient $\mathrm{D}_{\mathrm{Al}}$ and $\mathrm{C}_{\gamma}$ concentration of the model using the Inverse Problem Solution method. The estimated parameters value were: $\mathrm{D}_{\mathrm{A} 1}=7.12 \times 10^{-14}, \mathrm{~m}^{2} \mathrm{~s}^{-1}, \mathrm{C}_{\gamma}=3.65, \%$ at $950{ }^{\circ} \mathrm{C} . \mathrm{C}_{\gamma}$ concentration does not change with time, but different for other temperatures.

A prediction for $10000 \mathrm{~h}$ was calculated with the model ${ }^{4}$ using model parameters estimated from the data after $700 \mathrm{~h}$ and compared with the experimentally obtained Al concentration profile (Fig. 6).

Figure 7 gives predicted and measured beta phase concentrations during oxidation. The time $\approx 24000 \mathrm{~h}$ means coating lifetime end at $950{ }^{\circ} \mathrm{C}$. The time $\approx 72000 \mathrm{~h}$ is coating lifetime end at $900{ }^{\circ} \mathrm{C}$. The calibrated model with the ISP technique also allows the beta phase life prediction for various coating thicknesses during oxidation (see Fig. 8).

\section{Conclusions}

1. The approach by the Inverse Problem Solution showed to be a technically easily feasible way to obtain input values for the model parameter estimation.

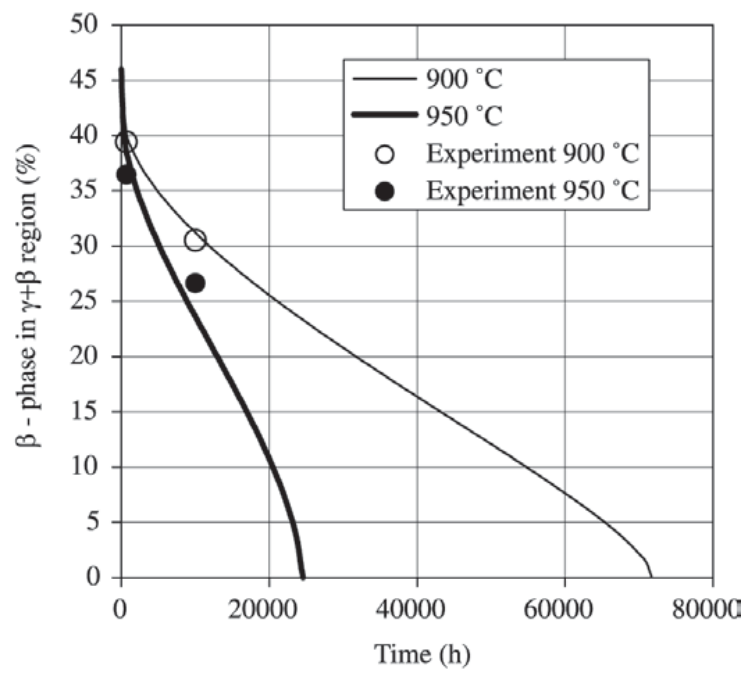

Figure 7. The predicted and measured beta phase concentration during oxidation for coating thickness 200 micron at $950{ }^{\circ} \mathrm{C}$ and $900{ }^{\circ} \mathrm{C}$. 


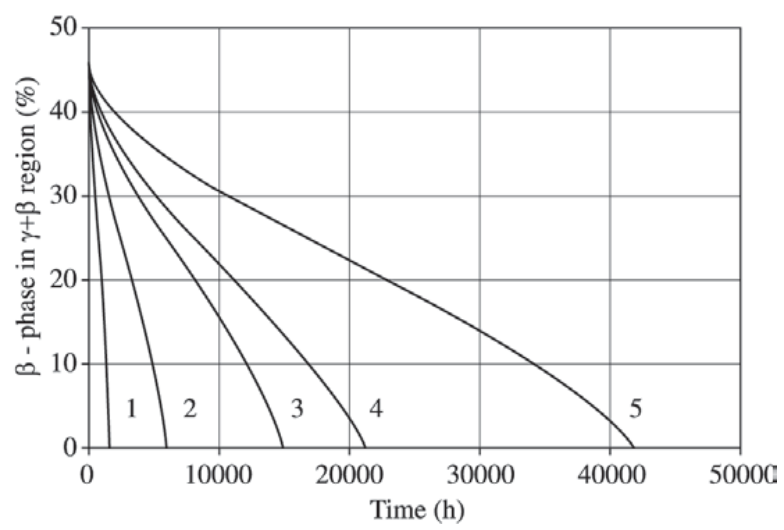

Figure 8. The predicted beta phase amount for various coating thicknesses during isothermal oxidation at $950{ }^{\circ} \mathrm{C}$. (1) curve is 50 micron; (2) is 100 micron; (3) is 150 micron; (4) is 175 micron; (5) is 250 micron.

2. The model calibrated by the Inverse Problem Solution Technique and short time experimental data can be used for long time modeling and prediction of oxidation and diffusion processes in MCrAlY coatings.

3. The diffusion coefficients estimated and used in the model are effective diffusion coefficients representing the real processes in the coating under the given conditions.

\section{Acknowledgements}

The authors would like to thank NATO for the support of the research work and W. Stamm and S. Alpérine for their contribution in numerous discussions.

\section{References}

1. Streiff, R. High Temperature Corrosion 3, Streiff, R.; Stringer, J.; Krutenat, R.C.; Caillet Eds, M. J. Phys. (France) IV, Colloque C9, v. 3, p. 17-41, 1993.

2. Beele, W.; Czech, N.; Quadakkers, W.J.; Stamm, W. Surf. Coat. Technol., v. 41, p. 94-95, 1997.

3. Nesbitt, J.A. Numerical Modeling of High-Temperature Corrosion Processes, Oxidation of Metals, v. 44, p. 309338, 1996.

4. Lee, E.Y.; Chartier, D.M.; Biederman, R.R.; Sisson Jr., R.D. Modelling the microstructural evolution of $\mathrm{M}$ - $\mathrm{Cr}$ Al-Y coatings during high temperature oxidation. Surface and coatings technology, v. 32, p. 19-39, 1987.

5. Nesbitt, J.A.; Heckel, R.W. Interdiffusion in Ni-Rich, NiCr-Al Alloys at 1100 and $1200{ }^{\circ} \mathrm{C}$ : Part II. Diffusion Coefficients and Predicted Concentration Profiles, Met. Trans. 18A, December, 1987.

6. P. Krukovsky, V. Kolarik, K. Tadlya, A. Rybnikov, I. Kryukov, M. Juez-Lorenzo Lifetime Modelling of High Temperature Corrosion Processes. Proceedings of an EFC Workshop, 231-245, (2001).

7. Krukovsky, P.G.; Kartavova, E.S. Inverse Problems in Engineering. Theory and Practice, ASME, p. 403-408, 1999. 